\title{
Right inferior phrenic artery injury as a complication of needle aspiration: a case report
}

\author{
Mohamed El Adel ${ }^{1 *} \mathbb{D}$, Sayed Hassan², Mohamed A. Nady ${ }^{1}$, Ahmed Ghoneim and Hany Seif ${ }^{2}$
}

\begin{abstract}
Background: To the best of the author's knowledge, inferior phrenic artery injury was not documented in the literature as a complication of chest tube insertion or needle aspiration, and our case was the first to be mentioned in literature.

Traumatic injury to the inferior phrenic artery is extremely rare. It was reported to be injured by blunt trauma such as motorcar accident and may be associated with another organ injury.

Case presentation: The present case represents an unexpected event of inferior phrenic artery injury due to iatrogenic chest aspiration. Despite the safe maneuver we have approached in our center using a blunt dissection technique rather than the trocar technique, an unexpected complication occurred. The right inferior phrenic artery was injured with subsequent intra-abdominal bleeding and shock. It was treated successfully by endovascular embolization of the bleeding artery.

Conclusions: This complication might add a further morbidity and mortality and raising the responsibility of the surgeon to one of the most common daily surgeon's practices.
\end{abstract}

Keywords: Inferior phrenic artery, Chest aspiration, Chest tube, Transcatheter arterial embolization

\section{Background}

Traumatic injury to the inferior phrenic artery is extremely rare. It was reported to be injured by blunt trauma such as motorcar accident [1] and may be associated with another organ injury [2]. The present case represents an unexpected event of inferior phrenic artery injury due to iatrogenic chest aspiration. This complication might add a further morbidity and mortality and raising the responsibility of the surgeon to one of the most common daily surgeon's practices.

\section{Case presentation}

A female patient 21 years old was diagnosed by transthoracic echocardiography and computed tomography angiography (CTA) as Fallot's tetralogy with absent pulmonary

\footnotetext{
* Correspondence: eladel91@aun.edu.eg; eladel91@yahoo.com

${ }^{1}$ Cardiothoracic Surgery Department, Assiut University Hospital, Asyut, Egypt

Full list of author information is available at the end of the article
}

valve. She underwent surgical reconstruction of the pulmonary valve with a tissue valve and Fallot repair. After an uneventful recovery, she returned to our department at the 55th day after the operation with high grade fever. Diagnosis of infective endocarditis based on echocardiographic finding of a big mass $(3.4 \times 1.7 \mathrm{~cm})$ attached to pulmonary tissue valve resulting in severe pulmonary stenosis (PG = $77.1 \mathrm{mmHg}$ ) and leukocytosis on blood picture. Therefore, the patient underwent a second operation on the second day after presentation with insertion of a valved Dacron graft on the infundibulum of right ventricular outflow tract.

Three days postoperatively, the patient developed extensive pneumonia that was treated by an extensive course of broad-spectrum antibiotics. Four days after surgery, we notice a blunt angle on the right side of the chest $\mathrm{x}$-ray. Chest aspiration was done to detect the exact site of effusion, and then right intercostal tube was inserted using the blunt dissection technique.

\section{Springer Open}

(-) The Author(s). 2021 Open Access This article is licensed under a Creative Commons Attribution 4.0 International License which permits use, sharing, adaptation, distribution and reproduction in any medium or format, as long as you give appropriate credit to the original author(s) and the source, provide a link to the Creative Commons licence, and indicate if changes were made. The images or other third party material in this article are included in the article's Creative Commons licence, unless indicated otherwise in a credit line to the material. If material is not included in the article's Creative Commons licence and your intended use is not permitted by statutory regulation or exceeds the permitted use, you will need to obtain permission directly from the copyright holder. To view a copy of this licence, visit http://creativecommons.org/licenses/by/4.0/. 
Three hours after aspiration and insertion of a chest tube, we noticed continuous trickling of blood from chest drain, and the patient became hemodynamically unstable with hemoglobin level dropping from 10.5 to 7 $\mathrm{mg} / \mathrm{dl}$. Urgent bedside sonar revealed a significant amount of collection in the right anterior and posterior subphrenic spaces. The patient underwent contrastenhanced computed tomography (CE-CT) of the abdomen which revealed large subcapsular hepatic and sub- phrenic hematomas with extravasation of contrast media within the hematoma (Fig. 1) raising the possibility of traumatic active arterial bleeding.

After that, we prepared the patient for angioembolization after consultation of the Interventional Radiology team. Endovascular procedure started by insertion of 5 French (Fr) arterial sheath in the right femoral artery. A 5 Fr Cobra catheter was used to catheterize the hepatic artery, searching for injury through puncture of the
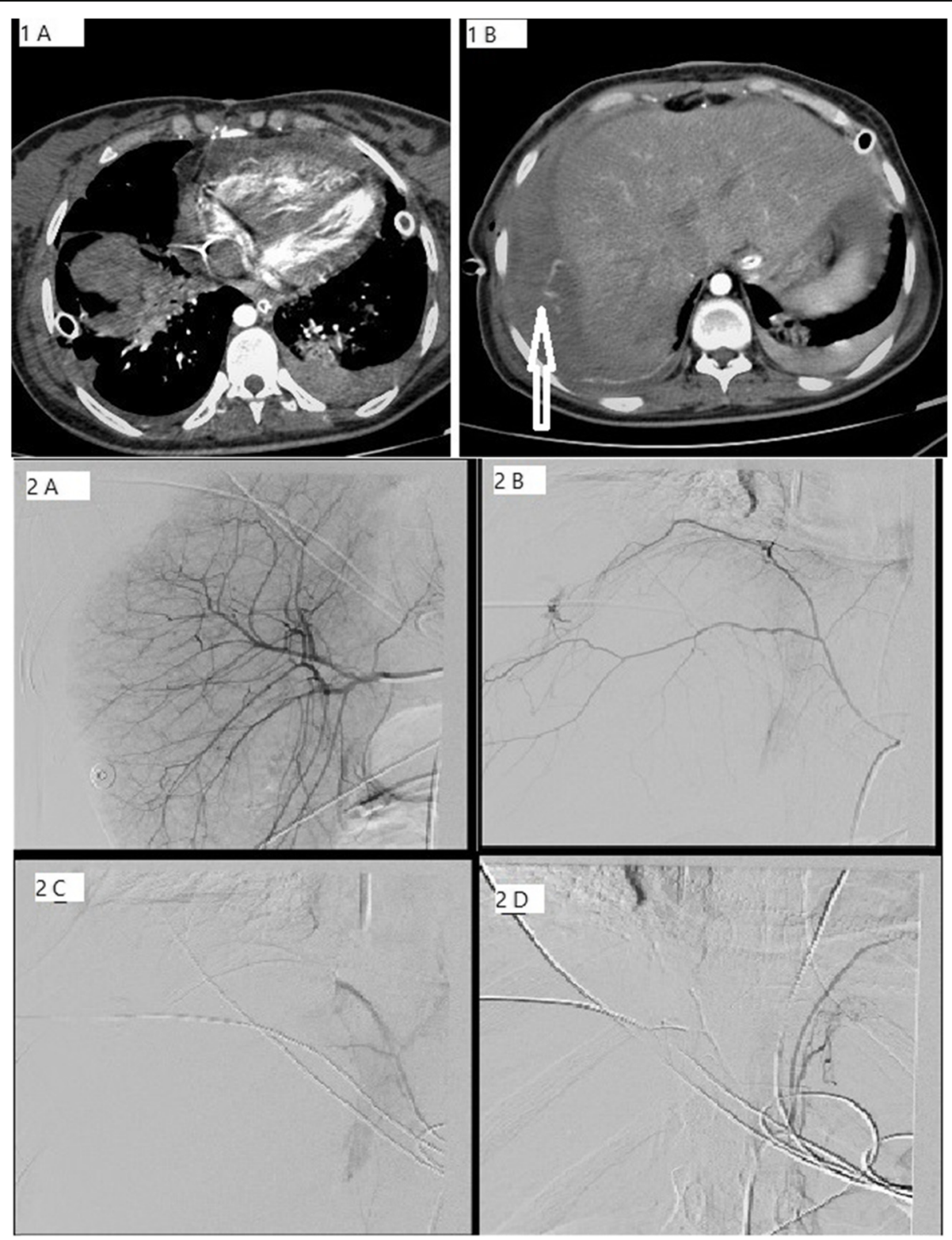

Fig. 1 1A, 1B Axial contrast-enhanced CT—chest and abdomen (arterial phase). 1A Evidence of right lower lung lobe consolidation and left sided pleural effusion. 1B Evidence of active contrast extravasation (white arrow) within high density right subphrenic hematoma. 2A Selective catheter hepatic angiogram revealed no evidence of contrast extravasation. 2B Selective right inferior phrenic artery angiogram revealed evidence of contrast extravasation form the lateral branch of the RIPA. 2C Micro-catheter super selective embolization with small PVA particles of the RIPA bleeding branch with disappearance of the extravasation. 2D further embolization of the RIPA main trunk using N-Butyl cyanoacrylate (NBCA) -lipiodol mixture 


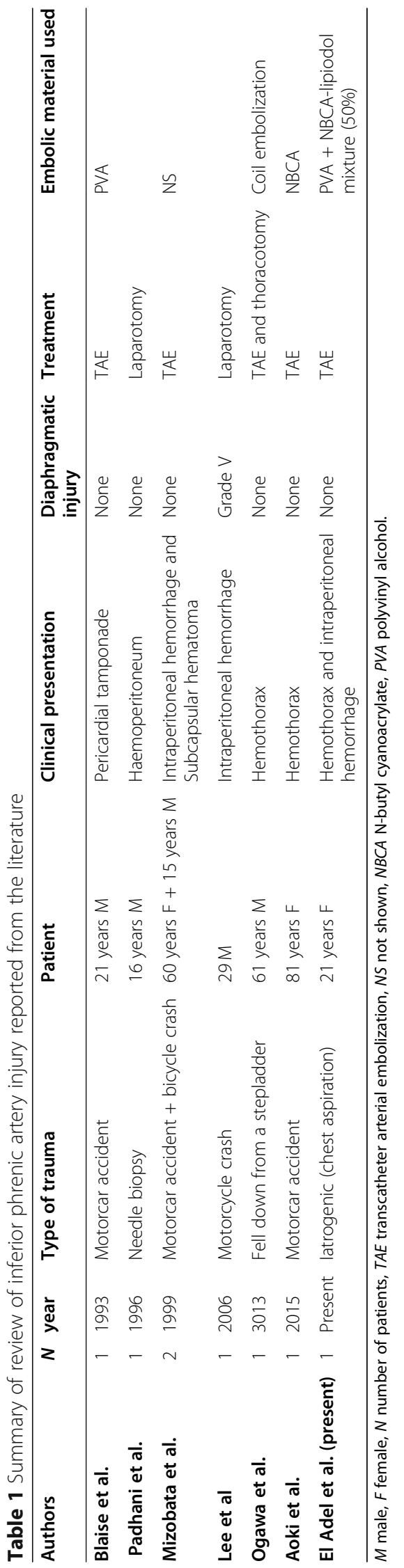


hepatic parenchyma. The hepatic angiogram was normal as we could not identify any contrast extravasation. Then we catheterized the right inferior phrenic artery that showed extravasation from its lateral branch. A 2.4 Fr microcatheter (Renegade, Boston Scientific, USA) was introduced through the cobra catheter towards the injured branch and used to deliver polyvinyl alcohol particles (PVA) distally, then the main trunk was permanently embolized using N-Butyl cyanoacrylate (NBCA) lipiodol mixture (50\%) (Fig. 1).

Two hours after the angioembolization, the amount of bleeding in the right chest drain dramatically decreased, and she became hemodynamically stable, with no further drop of the hemoglobin concentration. The patient underwent daily bedside sonar that showed decreasing the amount of the intra-abdominal collection. The patient was successfully extubated after 2 days of embolization, but the pneumonia was not improving, so alternating vent and continuous positive airway pressure (CPAP) mask were putted on.

Despite the successful surgery and successful management of complications, the patient died 5 days later from respiratory muscle fatigue due to extensive pneumonia despite meticulous observation and management.

\section{Discussion}

Between the 12th thoracic vertebrae and 2nd lumbar vertebrae, the inferior phrenic artery usually originates. The right and left branches may arise from the celiac trunk, aorta, renal artery, and left gastric or hepatic artery proper. The inferior phrenic artery gives rise to about eight branches: ascending artery, descending artery, inferior vena cava, esophageal branch, diaphragmatic hiatal, superior or middle suprarenal, and accessory splenic [3]. Until the present moment, only seven cases of inferior phrenic artery injury (excluding our case) were reported, and each case has a different clinical scenario and condition (Table 1) [1, 2, 4-6]. Hemothorax due to inferior phrenic artery injury rarely occurs, and only two cases were previously reported in the literature $[1,5]$, and our case may be the third one. The mechanism here explained by injury of right inferior phrenic artery led to hemorrhage in the mediastinum, which opened from a previous cardiac operation with subsequent rupture in right pleural sac, causing hemothorax and continuous trickling from the intercostal tube after insertion.

Transcatheter arterial embolization (TAE) is considered the appropriate management for inferior phrenic artery injury, if the injury was not associated with diaphragmatic rupture or herniation of the stomach. It can abolish the prerequisites for laparotomy and thoracotomy that were only needed in one case $[2,4]$.
To the best of the author's knowledge, it is the first documented case in the literature caused by iatrogenic percutaneous chest aspiration of pleural effusion. It was unbelievable except after evident $\mathrm{CT}$ and angiographic examination.

\section{Conclusion}

Inferior phrenic artery injury should be kept in mind in any case with chest aspiration and drain insertion. The surgeon should have a low threshold to this complication if there are intra-peritoneal collection, hemothorax, and hemodynamic instability.

\section{Abbreviations \\ CTA: Computed tomography angiography; CE-CT: Contrast-enhanced computed tomography; Fr: French; PVA: Polyvinyl alcohol particles; NBCA: N- Butyl cyanoacrylate; CPAP: Continuous positive airway pressure; \\ TAE: Transcatheter arterial embolization; RIPA: Right inferior phrenic artery}

\section{Acknowledgements}

Not applicable

\section{Authors' contributions}

All authors ("ME," "AF," "MAN") have contributed significantly to the content of the article. All authors analyzed and interpreted the patient data and help in writing the manuscript. The manuscript has not previously been published in print or electronic form and is not under consideration by any other publication. All authors have read and approved the submission of the manuscript to The Cardiothoracic Surgeon journal. There is no ethical problem or conflict of interest.

\section{Funding}

The research has no funding.

\section{Availability of data and materials}

All data generated or analyzed during this study are included in this published article

\section{Ethics approval and consent to participate}

The patients are HIPAA de-identified and do not require Institutional Research Board (IRB).

\section{Consent for publication}

The patients are HIPAA de-identified and do not require a consent or IRB https://www.hhs.gov/hipaa/for-professionals/privacy/special-topics/deidentification/index.html?fbclid=IwAR2GWs3eZD8xm24

Boxq8ovTOLcgwkxFvGepE2EF-pa-ukfWr-3mtXj7cga4\#standard

\section{Competing interests}

There are no financial competing interests.

\section{Author details}

${ }^{1}$ Cardiothoracic Surgery Department, Assiut University Hospital, Asyut, Egypt.

${ }^{2}$ Radiology Department, Assiut University Hospital, Asyut, Egypt.

Received: 28 October 2020 Accepted: 28 February 2021

Published online: 11 March 2021

\section{References}

1. Aoki M, Shibuya K, Kaneko M, Koizumi A, Murata M, Nakajima J et al (2015) Massive hemothorax due to inferior phrenic artery injury after blunt trauma. World J Emerg Surg 10:58

2. Lee JW, Kim S, Kim CW, Kim KH, Jeon TY (2006) Massive hemoperitoneum due to ruptured inferior phrenic artery pseudoaneurysm after blunt trauma. Emergency radiology 13:147-149

3. Loukas M, Hullett J, Wagner T (2005) Clinical anatomy of the inferior phrenic artery. Clinical Anatomy 18:357-365 
4. Padhani AR, Scott WW Jr (1996) Case report: Phrenic artery injury--a rare complication of percutaneous needle lung biopsy. The British journal of radiology 69:356-358

5. Mizobata Y, Yokota J, Yajima Y, Sakashita K (2000) Two cases of blunt hepatic injury with active bleeding from the right inferior phrenic artery. Journal of Trauma and Acute Care Surgery 48:1153-1155

6. Ogawa F, Naito M, lyoda A, Satoh Y (2013) Report of a rare case: occult hemothorax due to blunt trauma without obvious injury to other organs. Journal of cardiothoracic surgery 8:205

\section{Publisher's Note}

Springer Nature remains neutral with regard to jurisdictional claims in published maps and institutional affiliations.

\section{Submit your manuscript to a SpringerOpen ${ }^{\circ}$ journal and benefit from:}

- Convenient online submission

- Rigorous peer review

- Open access: articles freely available online

- High visibility within the field

- Retaining the copyright to your article

Submit your next manuscript at $\boldsymbol{\nabla}$ springeropen.com 